\title{
THE EFFECT OF CLAY AMENDMENT ON SUBSTRATE PROPERTIES AND GROWTH OF WOODY PLANTS
}

\author{
T. Meisl, M. Dubský, F. Šrámek, T. Nečas \\ Received: September 13, 2012
}

\begin{abstract}
MEISL, T., DUBSKÝ, M., ŠRÁMEK, F., NEČAS, T.: The effect of clay amendment on substrate properties and growth of woody plants. Acta univ. agric. et silvic. Mendel. Brun., 2012, LX, No. 8, pp. 163-170

This work deals with the effect of two clay products differing in particle size distribution on properties of growing substrate and on growth of containerized woody plants in substrates amended with these clay products. Fine and coarse clay were added to a peat substrate, each at two rates. The peat substrate without clay was used as a control. The substrates were tested in experiments with two woody ornamentals (Thuja occidentalis 'Smaragd' and Prunus cistena). Chemical and physical properties of the substrates were measured according to European Standards before planting. Proportion of water categories differing in availability to the plants were calculated from retention curves measured on the sand box. Properties of substrates in containers with and without plants were evaluated in the same way at the end of the culture. Clay addition changed chemical and physical properties of the tested substrates in terms: available nutrients content, particle density, bulk density, total pore volume, easy available water, water buffering capacity, air capacity, and shrinkage. The effect of fine clay was much stronger. In comparison with the clear effect of clay addition on the substrate chemical and physical properties, the effect on the growth and quality of model woody plants was not so explicit.
\end{abstract}

growing substrate, physical properties, chemical properties, retention curves, peat, clay

Clay and other mineral components are used as additives to growing media for changing their chemical and physical properties. Various types of clay differ in cation exchange capacity (CEC) depending on their mineral composition (Grantzau, 1998a). Added to substrates clay increases retention of nutrients and decreases leaching, thus it improves nutrition of cultivated crops (Verhagen, 2004). On the other hand clay addition can lower the available phosphorus content. It was supposed that phosphate could be bound with iron and aluminium in a ligand structure, or precipitated with calcium or magnesium. It could be the cause of more compact growth in substrates amended with clay (Grantzau, 1998a; Verhagen, 2004).

The optimal $\mathrm{pH}$ of clay or other mineral components is slightly acid or neutral, connected with low carbonate content $<0.3 \%$. The cation exchange capacity (CEC) of clays is influenced by the content of clay minerals. Montmorillonite has the highest CEC 0.7-1.3 mmol . $^{-1}$, CEC of illite ranges from 0.2 to $0.5 \mathrm{mmol}^{+} . \mathrm{g}^{-1}$ and kaolinite has the lowest CEC 0.03-0.05 mmol+. $\mathrm{g}^{-1}$. High CEC of natural clays is $>0.3 \mathrm{mmol}^{+} . \mathrm{g}^{-1}$ (Grantzau, 1998a). From mineral components zeolites have the highest CEC, it ranges from 1 to $2 \mathrm{mmol}^{+}$. $\mathrm{g}^{-1}$ (Kolar et al., 2010).

Clay addition to peat substrates also has a great impact on the water holding characteristics and water uptake. Verhagen (2004) observed very strong effect of fine graded clay which decreased easy available water (EAW) and had a great influence on water uptake in very dry conditions. The effect of coarse graded clay was much weaker and higher doses were required. He claimed that growth reduction usually observed in substrates amended with clay was often the consequence of clay's physical effect because he found a significant correlation between EAW and growth of impatiens plants. 
Also granulated or powdered zeolites added to growing media reduced total pore space (porosity), air volume and EAW. The effect of granulated zeolites was weaker, so growing media with granulated zeolites had better levels of air volume than those with powdered zeolites at the same percentage (Cativello, 1995; Kolar et al., 2010).

Martínez et al. (1997) observed that clay addition to the peat-coir mixture increased water volume at $1 \mathrm{kPa}$ water tension, EAW and available water and decreased total pore space and air capacity. In this case, in substrates with high air space, it did not depend on clay grading, granulated and powdered clay showed the same effect.

In manufactured professional organic substrates with mineral components the rate of clay ranges from 30 to $200 \mathrm{~kg} \cdot \mathrm{m}^{-3}$ of substrate. The rate $200 \mathrm{~kg} . \mathrm{m}^{-3}$ approximately corresponds to $20 \%$ vol. The substrate producers use high-quality mineral materials with define particle size distribution (fine or coarse) and high CEC. The growers of woody plants for landscape horticulture use mixtures with a high content (up to 50\% vol.) of mineral components (soil, loess loam). Disadvantages include high bulk density and usually low air content in these substrates (Šrámek et al., 2010).

Peat and peat-bark substrates work well for container production but a different situation comes after transplanting into soil. These substrates have high content of easily available water (EAW). It is bound by weak forces and after transplanting original root balls usually lose a substantial amount of water which moves into the surrounding backfillsoil (Hanson et al., 2004). Containerized woody plants grown in luxuriant conditions are not adapted to water stress after transplanting. There is a significant problem caused by the drying of purepeat root balls because their re-wetting capability is very poor. That is why woody plants for landscape planting are often grown in substrates amended with clay or soil. Such types of substrates have lower EAW content and during cultivation plants can adapt to stressful post-transplant conditions. Plants grown in these types of substrates were able to withstand water stress after transplanting better (Pastor et al., 1999; Šrámek et al., 2010).

The aim of the work was to compare the effect of clays differing in particle size distribution on the physical and chemical properties of peat based growing media and on the growth of containerized woody and to discover how the physical and chemical properties are influenced by the sampling term and the preparation of the sample.

\section{MATERIAL AND METHODS}

\section{Growing substrates}

Four peat substrates amended with clay were compared with peat-based control $\mathrm{P}$ which consisted of Lithuanian blonde and black peat (ratio by $\%$ vol. 70/30), both fractioned into 0-20 mm. Two types of clay were used, fine clay (bentonite) with trade name Ekobent (supplier Keramost, a. s., Obrnice, Czech Republic) and coarse-grained clay with trade name Florisol (supplier Stephan Schmidt Gruppe, Dornburg, Germany). Fine clay was added at the rate of 50 and $100 \mathrm{~kg} \cdot \mathrm{m}^{-3}$ (treatments F50 and F100), coarse clay at the rate of 100 and 200 kg.m ${ }^{-3}$ (treatments C100, C200), all values corresponded to dry matter weight. Bulk density (BD) (EN 13040) of fine clay was 870 g.l-1 , and BD of coarse clay was 1280 g. $\mathrm{l}^{-1}$. Dry matter of $100 \mathrm{~kg}$ of fine and coarse clay corresponded to 115 and 78 litres, respectively, of clay with natural moisture. Substrates were prepared on the pilot production line with a sorter (diameter of the sieve $20 \mathrm{~mm}$ ).

Fine clay had $\mathrm{pH} / \mathrm{CaCl}_{2}$ value (ISO 10390) 7.7, CEC (ISO 13536) $0.48 \mathrm{mmol}^{+} . \mathrm{g}^{-1}$ and carbonate content (ISO 10693) $0.3 \%$, coarse clay had $\mathrm{pH} / \mathrm{CaCl}_{2}$ value 7.5, CEC $0.13 \mathrm{mmol}^{+} . \mathrm{g}^{-1}$ and carbonate content $0.2 \%$. The higher CEC of fine clay was caused by higher content of illite and montmorillonite compared to coarse clay (the phase analysis, system XRD 3000 P, goniometr with Bragg-Brentan focusing arrangement). According to particle size analysis (DIN 11540) the coarse clay had high proportion (85\%) of fraction $>2 \mathrm{~mm}$ (Tab. I).

The substrates were preplant incorporated with $1.5 \mathrm{~kg} . \mathrm{m}^{-3}$ soluble NPK fertilizer (14\% N, 7\% P, 15\% K) containing micronutrients. Control peat substrate was provided with $6 \mathrm{~kg} \mathrm{~m}^{-3}$ dolomitic limestone for $\mathrm{pH}$ adjustment. According to the chemical properties of clay materials the rate of dolomitic limestone was decreased in substrates with clay to $4 \mathrm{~kg} \mathrm{~m}^{-3}$ (treatments F50, C100, and C200) and $3 \mathrm{~kg} \cdot \mathrm{m}^{-3}$ (treatment Fl00).

\section{Chemical and physical properties}

The substrates were analysed for chemical properties according to European Standards. Electric conductivity (EC) (EN 13 038), pH value (EN 13037), and content of available calcium (EN 13652) were determined in water extract (1:5 volvol), content of other available nutrients (EN 13 651) by CAT extraction $\left(0.01 \mathrm{~mol}^{-1} \mathrm{C}^{-1} \mathrm{CaCl}_{2}\right.$ and $0.002 \mathrm{~mol}$. $\mathrm{l}^{-1}$ DTPA) with an extraction ratio of $1: 5$ vol-vol. The samples were taken before planting and application of controlled release fertilizers (CRF) and at the

I: Particle size analysis (DIN 11540) of the tested clay products

\begin{tabular}{lcccccc}
\hline \multirow{2}{*}{ Clay material } & \multicolumn{5}{c}{ fraction, ratio in \% } \\
\cline { 2 - 6 } & $\mathbf{0 - 0 . 5} \mathbf{~ m m}$ & $\mathbf{0 . 5 - 1 ~} \mathbf{~ m m}$ & $\mathbf{1 - 2} \mathbf{~ m m}$ & $\mathbf{2 - 5} \mathbf{~ m m}$ & $\mathbf{5} \mathbf{~ m m}$ \\
\hline Fine clay (Ekobent) & 43 & 27 & 30 & 0 & 0 \\
Coarse clay (Florisol) & 5 & 3 & 7 & 55 & 30 \\
\hline
\end{tabular}


beginning of September (36. week, 20 weeks after CRF application).

The physical properties of the substrates were evaluated in standard $5.3 \mathrm{~cm}$ high rings (EN 13 041). The moisture retention curves were measured in a sand box in the range of -0.25 to $-10 \mathrm{kPa}$ of water potential. Preparation and saturation of the substrates before planting were carried out according to EN 13 041, which was slightly modified. After the sample had been placed for 48 hours on the sand box at -1 kPa water potential (EN 13 041, paragraph 7.3), it was saturated once more. The upper ring was then removed and the fully saturated sample was put in the sand box $(-0.25 \mathrm{kPa})$.

For evaluation the changes of physical properties of the substrates during cultivation the rings were at planting (16. week) placed into the containers without plants and with Thuja plants. The rings were placed in the middle of the container on the $5 \mathrm{~cm}$ layer of the substrate. The containers were then filled with the substrate and placed on the growing area among experimental plants. The rings were lifted up at the end of the growing period (42. week), 26 weeks after planting. Then the substrate on the bottom surface of the ring was cut and fixed with synthetic gauze and a rubber band. The upper ring was put on the upper, non cut surface of substrate and the above mentioned saturation was done.

After measurement on the sand box, the sample was oven dried and dry bulk density (DBD) was calculated. The particle density for calculating the total pore space was measured using a water pycnometer and total pore space was calculated: $\mathrm{PS}=(\mathrm{PD}-\mathrm{BD}) \times 100 / \mathrm{PD}$, where $\mathrm{PS}$ is the total pore space (\% vol.), PD is the particle density $\left(\mathrm{kg}^{\left.-\mathrm{m}^{-3}\right)}\right.$ and $\mathrm{BD}$ is the bulk density $\left(\mathrm{kg} \cdot \mathrm{m}^{-3}\right)$. According to EN 13041 the shrinkage of substrate was measured. It characterizes the volume decrease of substrate after drying.

Air pore space and categories of water available to the plants were calculated: air pore space (AS) as the difference between the total pore space and the volume of water at water potential $-1 \mathrm{kPa}$, container (water) capacity (CC) as the volume of water (\% vol.) at water potential $-1 \mathrm{kPa}$, easily available water (EAW) as the volume of water (\% vol.) released from the growing medium when the water potential decreased from -1 to $-5 \mathrm{kPa}$, and water buffering capacity (WBC) as the volume of water (\% vol.) released from the growing medium when the water potential decreased from -5 to $-10 \mathrm{kPa}$ (De Boodt et al., 1974; Bohne and Wrede, 2005), and difficultly available water (DAW) as the volume of water (\% vol.) at water potential -10 kPa (Prasad and O'Shea, 1999).

\section{Vegetative experiment}

Substrates were tested in experiments with ornamental woody plants Thuja occidentalis 'Smaragd' and Prunus cistena cultivated outdoors in 2-litre containers for one vegetative period. Rooted cuttings grown in 0.5-litre container were cut to unified height of $16 \mathrm{~cm}$, the number of Prunus plants shoots was reduced to two. Before planting $4 \mathrm{~kg} / \mathrm{m}^{3}$ of controlled release fertilizer Osmocote standard 5-6 (15\% N, 4.4\% P, 8.3\% K) was added to each substrate.

The plants were planted at the end of April 2009 (week 16). The automatic sprinkler irrigation was the same in all treatments. The irrigation was controlled by automatic time switch unit Multirain, the capacitive sensors were placed in the edge plants in peat substrate. At the end of the experiment (half of November, 46. week) the plants were evaluated for fresh and dry weight, height and Prunus for width.

\section{Experimental design and data analysis}

The measurements of chemical and physical properties were carried out with three replications. Each treatment (type of substrate) of the vegetative experiment had 3 replications with 8 plants in each one. All the data sets were tested for normality and analysed by one-way and two-way (influence of type of substrate on physical properties) ANOVA and Duncan's Multiple Range Test for 5\% level of significance (Unistat 4.53).

\section{RESULTS AND DISCUSSION}

\section{Evaluation of chemical properties}

Addition of clay changed chemical properties of the substrates measured before planting as well as during the experiment. Before planting (Tab. II) the highest $\mathrm{pH}$ values were recorded in the substrates with fine clay, rather lower EC values were in the substrates with coarse clay. Regardless of the same fertilizer amount incorporated into all substrates, lower content of available nitrogen and mainly available phosphorus were determined in clay amended substrate. Lowering solubility of phosphorus by binding on clay materials was probably the cause of this fact (Grantzau, 1998b; Verhagen, 2004). The substrates with clay were lower in available potassium. It concerns mainly the substrates amended with coarse clay where higher clay rate could have an effect on potassium sorption as well as on EC lowering mentioned above. The substrates with fine clay were lower in available calcium probably due to high CEC of fine clay that decreased the amount of $\mathrm{Ca}$ extracted by water.

During the experiment apparent shift in measured values was recorded. Values of $\mathrm{pH}$ increased, they ranged from 7.1 to 7.3 in the treatments $\mathrm{P}, \mathrm{Cl00}$, and C200, and from 7.5 to 7.6 in the F50 and F100. Significant differences were between $\mathrm{P}$ and the treatments F50 and F100. EC values in all treatments dropped into the range of $0.8-0.11 \mathrm{mS} . \mathrm{cm}^{-1}$. Available nutrient content was also lower than at the beginning. Available nitrogen content was 40-60 mg.l $\mathrm{l}^{-1}$ in all treatments sampled from both species. Available potassium was lower, unlike the start of the experiment. The significantly higher values were recorded in the substrates with the fine clay (65-75 mg.l $\mathrm{l}^{-1}$ in F50 and Fl00, 25-30 mg.l $\mathrm{l}^{-1}$ 
II: Chemical properties of the substrates before planting, optimum range (Alt, 1994; Šrámek et al., 2010) of available nutrients by CAT extraction, means followed by the same letter are not significantly different according to Duncan's Multiple Range test, $p<0.05$

\begin{tabular}{|c|c|c|c|c|c|c|c|c|c|c|c|c|c|c|c|c|c|c|}
\hline \multirow{3}{*}{$\begin{array}{l}\text { treatment } \\
\mathrm{P}\end{array}$} & \multirow{2}{*}{\multicolumn{2}{|c|}{ pH }} & \multirow{2}{*}{\multicolumn{2}{|c|}{$\frac{\text { EC }}{\text { mS.cm }^{-1}}$}} & \multicolumn{2}{|c|}{$\mathbf{N}-\mathbf{N H}_{4}$} & \multicolumn{2}{|c|}{$\mathrm{N}-\mathrm{NO}_{3}$} & \multicolumn{2}{|c|}{$\operatorname{sum} \mathbf{N}$} & \multicolumn{2}{|c|}{$\mathbf{P}$} & \multicolumn{2}{|c|}{$\mathbf{K}$} & \multicolumn{2}{|c|}{ Mg } & \multicolumn{2}{|c|}{$\mathrm{Ca}$} \\
\hline & & & & & \multicolumn{14}{|c|}{ mg.l $l^{-1}$ substrate } \\
\hline & 6.5 & $\mathrm{~b}$ & 0.32 & $\mathrm{a}$ & 79 & $\mathrm{a}$ & 121 & $\mathrm{a}$ & 200 & $\mathrm{a}$ & 63 & $\mathrm{a}$ & 129 & $\mathrm{a}$ & 346 & $\mathrm{a}$ & 43 & $\mathrm{a}$ \\
\hline F50 & 6.7 & a & 0.32 & a & 64 & $a b$ & 95 & b & 160 & $\mathrm{~b}$ & 25 & $\mathrm{~cd}$ & 118 & $\mathrm{~b}$ & 264 & a & 14 & $\mathrm{c}$ \\
\hline F100 & 6.7 & a & 0.31 & a & 56 & $\mathrm{~b}$ & 88 & b & 145 & b & 21 & $d$ & 118 & $\mathrm{~b}$ & 285 & a & 13 & $\mathrm{c}$ \\
\hline $\mathrm{ClO0}$ & 6.2 & $\mathrm{c}$ & 0.27 & b & 60 & $\mathrm{~b}$ & 84 & b & 144 & $\mathrm{~b}$ & 33 & $\mathrm{~b}$ & 91 & $\mathrm{c}$ & 342 & $\mathrm{a}$ & 30 & $\mathrm{~b}$ \\
\hline $\mathrm{C} 200$ & 6.2 & $\mathrm{c}$ & 0.26 & $\mathrm{~b}$ & 78 & $\mathrm{a}$ & 82 & $\mathrm{~b}$ & 160 & $\mathrm{~b}$ & 26 & $\mathrm{c}$ & 88 & c & 341 & $\mathrm{a}$ & 31 & b \\
\hline optimum & \multicolumn{2}{|c|}{$5.5-6.5$} & \multicolumn{2}{|c|}{$0.3-0.4$} & \multicolumn{6}{|c|}{ sum N 120-200 } & \multicolumn{2}{|c|}{$40-90$} & \multicolumn{2}{|c|}{$120-180$} & \multicolumn{2}{|c|}{$80-160$} & \multicolumn{2}{|c|}{$40-120$} \\
\hline
\end{tabular}

in P, C100, and C200). Higher sorption at start and subsequent release during cultivation could explain this fact (Grantzau. 1998a). Available phosphorus content depended on cultivated plant species. At Prunus, control peat substrate was significantly higher in available phosphorus $(20 \mathrm{mg} / \mathrm{l})$ than clay amended substrates (11-15 mg. $\left.\mathrm{l}^{-1}\right)$. At Thuia, available phosphorus was very low (below 10 mg. ${ }^{-1}$ ) in all treatments.

\section{Evaluation of hydrophysical properties}

Control peat substrate had optimal hydrophysical properties (Tab. III), measured values were within the ranges recommended for air space (20-30\% vol.) and easy available water (20-30\% vol.) by Verdonck at al. (1983) and for water buffering capacity (5-8\% vol.) and difficultly available water (30-40\% vol.) by Heiskanen (1995).

Addition of clay increased particle density and bulk density and decreased porosity of the substrates sampled before planting (Tab. III) as well as at the end of the experiment (Tab. IV, V). Clay products also substantially changed water holding characteristics, the effect of fine clay was much stronger in this respect. In the substrates sampled before planting fine clay increased DAW and decreased EAW, WBC, and AS, coarse clay only decreased AS and WBC, both to a lesser extent. It is consistent with results published by Verhagen (2004). In the substrates sampled at the end of the experiment the effect of both clay products was weaker than before planting (Tab. IV, V). Container capacity was an exception because effect of clay was only observed in the samples taken at the end of the experiment (Tab. IV, V). Shrinkage value was positively affected by addition of coarse clay, it was measured at the beginning as well as et the end of the experiment (Tab. II, IV, V).

As for CC, AS, and shrinkage value, there were apparent differences between the substrates sampled before planting and substrates sampled

III: Physical properties of substrates before planting, means followed by the same letter are not significantly different according to Duncan's Multiple Range test, $p<0.05$

\begin{tabular}{|c|c|c|c|c|c|c|c|c|c|c|c|c|c|c|c|c|c|c|}
\hline \multirow{3}{*}{$\begin{array}{l}\text { treatment } \\
\mathrm{P}\end{array}$} & \multirow{2}{*}{\multicolumn{2}{|c|}{$\frac{\text { PD }}{\text { g.ml }}$}} & \multirow{2}{*}{\multicolumn{2}{|c|}{$\begin{array}{l}\text { BD } \\
\text { g. } .^{-1}\end{array}$}} & \multicolumn{2}{|c|}{$\mathbf{P}$} & \multicolumn{2}{|c|}{ AS } & \multicolumn{2}{|c|}{ CC } & \multicolumn{2}{|c|}{ EAW } & \multicolumn{2}{|c|}{ WBC } & \multicolumn{2}{|c|}{ DAW } & \multicolumn{2}{|c|}{ shrinkage } \\
\hline & & & & & & & & & & & $\% \mathbf{v}$ & & & & & & & \\
\hline & 1.62 & e & 118 & $d$ & 92.7 & a & 16.7 & $\mathrm{a}$ & 76.1 & a & 27.1 & $a b$ & 9.8 & $\mathrm{a}$ & 39.2 & c & 48.0 & b \\
\hline F50 & 1.92 & d & 175 & $\mathrm{c}$ & 90.9 & b & 12.5 & $a b$ & 78.4 & a & 23.2 & $\mathrm{bc}$ & 8.3 & b & 46.9 & b & 52.8 & $\mathrm{a}$ \\
\hline F100 & 2.02 & c & 219 & b & 89.2 & c & 8.7 & $\mathrm{~b}$ & 80.4 & a & 22.7 & c & 7.0 & $\mathrm{c}$ & 50.8 & $\mathrm{a}$ & 54.4 & $\mathrm{a}$ \\
\hline $\mathrm{Cl} 00$ & 2.11 & b & 232 & b & 89.0 & c & 13.4 & $a b$ & 75.5 & $\mathrm{a}$ & 27.4 & $\mathrm{a}$ & 8.6 & b & 39.5 & c & 40.0 & $\mathrm{c}$ \\
\hline C200 & 2.26 & $\mathrm{a}$ & 312 & a & 86.2 & d & 7.9 & $b$ & 78.3 & a & 30.2 & a & 7.7 & bc & 40.4 & c & 39.0 & $\mathrm{c}$ \\
\hline
\end{tabular}

PD - particle density, BD - bulk density, P - porosity, AS - air space (content of air), CC - container capacity (water content), both at - $1 \mathrm{kPa}$ water potential, EAW - easily available water (difference between water content at -1 and $-5 \mathrm{kPa}$ water potential), WBC - water buffering capacity (difference between water content at 5 and $-10 \mathrm{kPa}$ water potential), DAW - difficultly available water (water content at - $10 \mathrm{kPa}$ water potential)

IV: Physical properties of substrates from containers without plants, means followed by the same letter are not significantly different according to Duncan's Multiple Range test, $p<0.05$

\begin{tabular}{|c|c|c|c|c|c|c|c|c|c|c|c|c|c|c|c|c|c|c|}
\hline \multirow{3}{*}{$\begin{array}{l}\text { treatment } \\
\mathrm{P}\end{array}$} & \multirow{2}{*}{\multicolumn{2}{|c|}{$\begin{array}{c}\text { PD } \\
\text { g.ml }^{-1}\end{array}$}} & \multirow{2}{*}{\multicolumn{2}{|c|}{$\frac{\text { DBD }}{\text { g. } \text { l }^{-1}}$}} & \multicolumn{2}{|c|}{$\mathbf{P}$} & \multicolumn{2}{|c|}{ AS } & \multicolumn{2}{|c|}{$\mathbf{C C}$} & \multicolumn{2}{|c|}{ EAW } & \multicolumn{2}{|c|}{ WBC } & \multicolumn{2}{|c|}{ DAW } & \multicolumn{2}{|c|}{ shrinkage } \\
\hline & & & & & & & & & & & $\% \mathrm{vc}$ & & & & & & & \\
\hline & 1.64 & $\mathrm{e}$ & 121 & $\mathrm{e}$ & 92.6 & a & 15.9 & a & 76.7 & bc & 27.1 & $\mathrm{a}$ & 6.5 & a & 43.1 & b & 37.1 & $\mathrm{c}$ \\
\hline $\mathrm{F} 50$ & 1.94 & d & 175 & d & 91.0 & b & 10.5 & b & 80.5 & $a b$ & 25.7 & $\mathrm{a}$ & 6.7 & a & 48.0 & a & 47.0 & b \\
\hline F100 & 2.13 & a & 251 & $b$ & 88.3 & d & 5.3 & $\mathrm{c}$ & 83.0 & a & 25.4 & a & 6.8 & a & 50.7 & $\mathrm{a}$ & 54.4 & $\mathrm{a}$ \\
\hline $\mathrm{Cl} 100$ & 2.07 & c & 223 & $\mathrm{c}$ & 89.2 & c & 14.6 & $a b$ & 74.7 & $\mathrm{~cd}$ & 26.5 & $\mathrm{a}$ & 6.8 & a & 41.3 & $\mathrm{~b}$ & 36.5 & $\mathrm{c}$ \\
\hline $\mathrm{C} 200$ & 2.31 & a & 338 & a & 85.4 & e & 15.5 & $a b$ & 69.9 & d & 23.5 & $\mathrm{a}$ & 6.1 & a & 40.3 & $\mathrm{~b}$ & 34.2 & $\mathrm{c}$ \\
\hline
\end{tabular}


V: Physical properties of substrates from containers with plants (Thuja), means followed by the same letter are not significantly different according to Duncan's Multiple Range test, $p<0.05$

\begin{tabular}{|c|c|c|c|c|c|c|c|c|c|c|c|c|c|c|c|c|c|c|}
\hline \multirow{3}{*}{$\begin{array}{l}\text { treatment } \\
\mathrm{P}\end{array}$} & \multirow{2}{*}{\multicolumn{2}{|c|}{$\frac{\text { PD }}{\text { g.ml }}$}} & \multirow{2}{*}{\multicolumn{2}{|c|}{$\begin{array}{c}\text { DBD } \\
\text { g.l }{ }^{-1}\end{array}$}} & \multicolumn{2}{|c|}{$\mathbf{P}$} & \multicolumn{2}{|c|}{ AS } & \multicolumn{2}{|c|}{$\mathrm{CC}$} & \multicolumn{2}{|c|}{ EAW } & \multicolumn{2}{|c|}{ WBC } & \multicolumn{2}{|c|}{ DAW } & \multicolumn{2}{|c|}{ shrinkage } \\
\hline & & & & & & & & & & & $\% \mathbf{v}$ & & & & & & & \\
\hline & 1.69 & $\mathrm{e}$ & 141 & $\mathrm{~d}$ & 91.7 & $\mathrm{a}$ & 15.1 & $\mathrm{a}$ & 76.6 & $a b$ & 29.3 & a & 5.7 & $\mathrm{a}$ & 41.6 & $\mathrm{bc}$ & 26.4 & $a b$ \\
\hline F50 & 1.91 & $d$ & 191 & $\mathrm{c}$ & 90.0 & b & 13.7 & $a b$ & 76.3 & $a b$ & 28.7 & $\mathrm{a}$ & 5.7 & a & 41.9 & b & 30.4 & $\mathrm{a}$ \\
\hline F100 & 2.06 & b & 238 & b & 88.4 & c & 14.1 & $a b$ & 74.3 & b & 24.6 & b & 5.0 & b & 44.6 & $\mathrm{a}$ & 31.3 & $\mathrm{a}$ \\
\hline $\mathrm{ClOO}$ & 2.02 & $\mathrm{c}$ & 229 & b & 88.7 & $\mathrm{c}$ & 9.2 & b & 79.5 & $\mathrm{a}$ & 29.4 & $\mathrm{a}$ & 5.8 & $\mathrm{a}$ & 44.3 & $\mathrm{a}$ & 23.4 & b \\
\hline C200 & 2.31 & $\mathrm{a}$ & 331 & a & 85.7 & $d$ & 16.3 & $\mathrm{a}$ & 69.4 & c & 25.1 & $b$ & 4.8 & $b$ & 39.4 & c & 20.6 & b \\
\hline
\end{tabular}

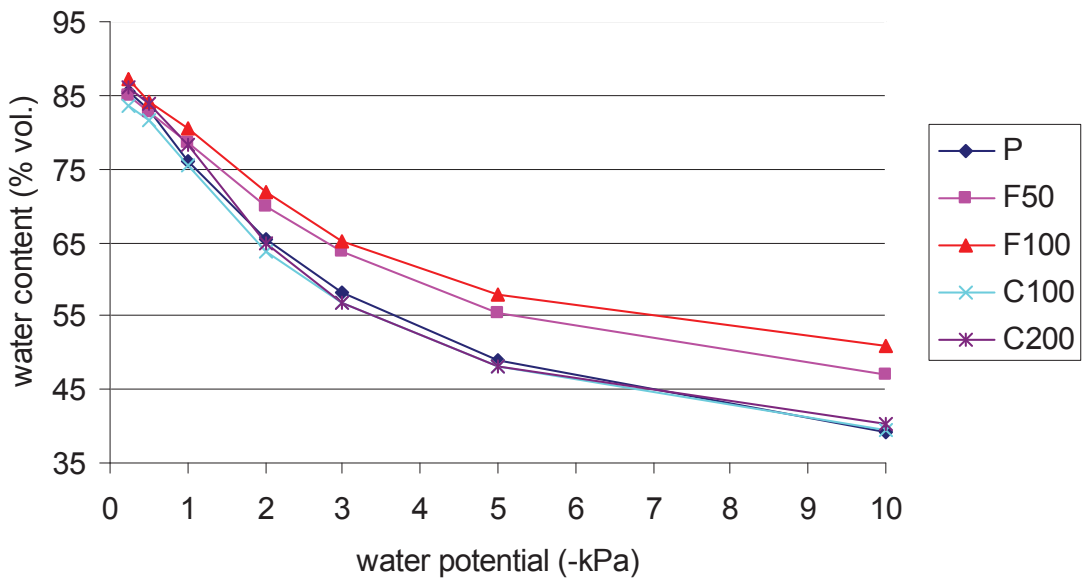

1: Moisture retention curves for the substrates before planting

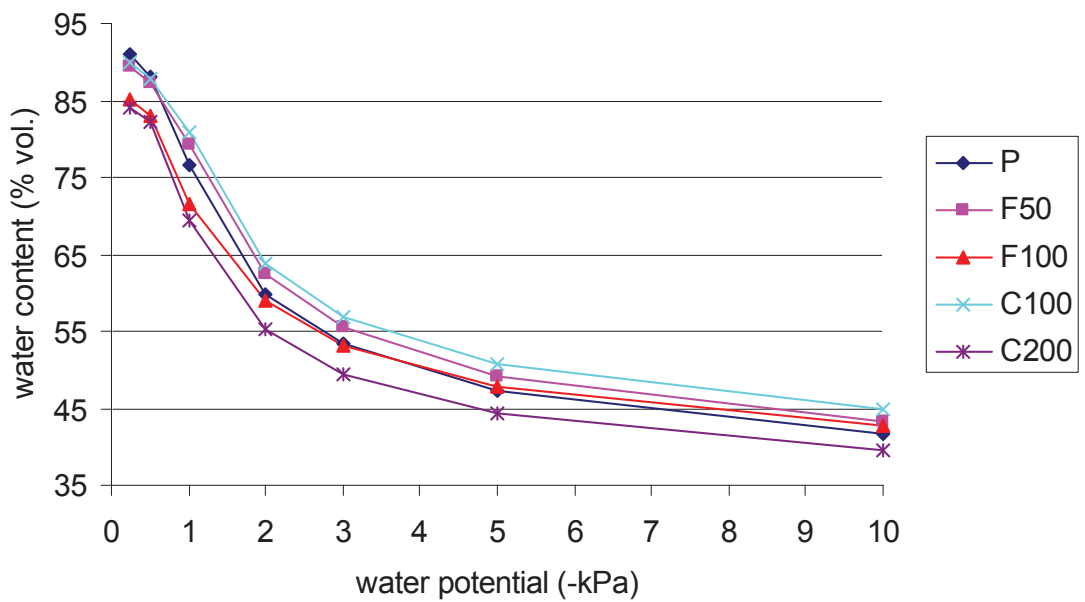

2: Moisture retention curves for the substrates from containers with plants

at the end of the experiment from containers with plants. It is summarized in Tab. VI. Air space measured in F50, F100, and C200 was higher than at the beginning, it was at the expense of CC. All substrates had more favourable shrinkage value when measured at the end, the peat substrate and the substrates with fine clay had higher BD. Differences in water retention ability between the substrates sampled before planting and at the end of the cultivation from container with plants are also well documented by shape of retention curves (Fig. 1, 2).

\section{Evaluation of plant growth}

Clay amendment had a significant effect on growth of Thuja plants. Cultivated in the substrates with clay, they were lower and had lower fresh and dry weight (Tab. VII). According to Grantzau (1998b) and Verhagen (2004) the cause could be worse phosphorus availability and/or lower volume of EAV in substrates with clay. In this experiment decrease in available phosphorus was recorded in all substrates amended with clay (Tab. II) whereas decrease in EAV was only in the substrates with fine clay (Tab. III). 
VI: Effect of sampling on physical properties of substrates. The substrates were sampled before planting (B) and at the end of cultivation from container without $(C)$ and with plants $(P)$. Means followed by the same letter are not significantly different within the type of substrate according to Duncan's Multiple Range test, $p<0.05$.

\begin{tabular}{|c|c|c|c|c|c|c|c|c|c|}
\hline \multirow{2}{*}{ treatment } & \multirow{2}{*}{ sampling } & \multicolumn{2}{|c|}{ BD } & \multicolumn{2}{|c|}{ AS } & \multicolumn{2}{|c|}{ CC } & \multicolumn{2}{|c|}{ shrinkage } \\
\hline & & \multicolumn{2}{|c|}{ g..$^{-1}$} & \multicolumn{6}{|c|}{ \% vol. } \\
\hline \multirow{3}{*}{$\mathrm{P}$} & B & 118 & b & 16.7 & $\mathrm{a}$ & 76.1 & $\mathrm{a}$ & 48.0 & $\mathrm{a}$ \\
\hline & $\mathrm{C}$ & 121 & $\mathrm{~b}$ & 15.9 & $\mathrm{a}$ & 76.7 & $\mathrm{a}$ & 37.1 & $\mathrm{~b}$ \\
\hline & $\mathrm{P}$ & 141 & $\mathrm{a}$ & 15.1 & $\mathrm{a}$ & 76.6 & $\mathrm{a}$ & 26.4 & $\mathrm{c}$ \\
\hline \multirow{3}{*}{ F50 } & B & 175 & $\mathrm{~b}$ & 12.5 & $a b$ & 78.4 & $a b$ & 52.8 & $\mathrm{a}$ \\
\hline & C & 175 & b & 10.5 & b & 80.5 & $\mathrm{a}$ & 47.0 & a \\
\hline & $\mathrm{P}$ & 191 & $\mathrm{a}$ & 13.7 & $\mathrm{a}$ & 76.3 & $\mathrm{~b}$ & 30.4 & $\mathrm{~b}$ \\
\hline \multirow{3}{*}{ F100 } & B & 219 & $\mathrm{~b}$ & 8.7 & $\mathrm{~b}$ & 80.4 & $\mathrm{~b}$ & 54.4 & a \\
\hline & C & 251 & $\mathrm{a}$ & 5.3 & $\mathrm{c}$ & 83.0 & $\mathrm{a}$ & 54.4 & $\mathrm{a}$ \\
\hline & $\mathrm{P}$ & 238 & $\mathrm{a}$ & 14.1 & $\mathrm{a}$ & 74.3 & $\mathrm{c}$ & 31.3 & $\mathrm{~b}$ \\
\hline \multirow{3}{*}{$\mathrm{ClOO}$} & B & 232 & $\mathrm{a}$ & 13.4 & $a b$ & 75.5 & b & 40.0 & a \\
\hline & $\mathrm{C}$ & 223 & a & 14.6 & $\mathrm{a}$ & 74.7 & b & 36.5 & a \\
\hline & $\mathrm{P}$ & 229 & $\mathrm{a}$ & 9.2 & $\mathrm{~b}$ & 79.5 & $\mathrm{a}$ & 23.4 & $\mathrm{~b}$ \\
\hline \multirow{3}{*}{ C200 } & B & 312 & a & 7.9 & $\mathrm{~b}$ & 78.3 & $\mathrm{a}$ & 39.0 & a \\
\hline & C & 338 & $\mathrm{a}$ & 15.5 & $a b$ & 69.9 & b & 34.2 & $\mathrm{~b}$ \\
\hline & $\mathrm{P}$ & 331 & $\mathrm{a}$ & 16.3 & $\mathrm{a}$ & 69.4 & $\mathrm{c}$ & 20.6 & c \\
\hline
\end{tabular}

VII: Evaluation of the plant growth (10.11.2009), means followed by the same letter are not significantly different according to Duncan's Multiple Range test, $p<0.05$

\begin{tabular}{|c|c|c|c|c|c|c|c|c|c|c|c|c|c|c|}
\hline \multirow{3}{*}{ treatment } & \multicolumn{8}{|c|}{ Prunus } & \multicolumn{6}{|c|}{ Thuja } \\
\hline & \multirow{2}{*}{\multicolumn{2}{|c|}{ fresh weight }} & \multicolumn{2}{|c|}{ dry weight } & \multicolumn{2}{|c|}{ height } & \multicolumn{2}{|c|}{ width } & \multicolumn{2}{|c|}{ fresh weight } & \multicolumn{2}{|c|}{ dry weight } & \multicolumn{2}{|c|}{ height } \\
\hline & & & $\mathrm{g}$ & & $\mathrm{cm}$ & & cn & & g & & g & & cr & \\
\hline $\mathrm{P}$ & 28.8 & $\mathrm{a}$ & 15.1 & $\mathrm{a}$ & 65.4 & bc & 25.6 & $\mathrm{a}$ & 121.2 & $\mathrm{a}$ & 49.9 & a & 52.9 & $\mathrm{a}$ \\
\hline F50 & 27.9 & $\mathrm{a}$ & 14.7 & a & 68.7 & $a b$ & 20.9 & $b$ & 95.8 & $\mathrm{c}$ & 38.6 & $\mathrm{bc}$ & 47.6 & bc \\
\hline F100 & 27.6 & $\mathrm{a}$ & 14.8 & a & 72.3 & $\mathrm{a}$ & 21.2 & $\mathrm{~b}$ & 104.9 & $\mathrm{~b}$ & 41.3 & $\mathrm{~b}$ & 48.9 & $\mathrm{~b}$ \\
\hline $\mathrm{Cl} 100$ & 29.2 & a & 15.3 & $\mathrm{a}$ & 71.2 & $a b$ & 19.1 & b & 90.3 & $\mathrm{c}$ & 37.7 & $\mathrm{c}$ & 42.6 & d \\
\hline C200 & 29.1 & a & 15.4 & $\mathrm{a}$ & 61.2 & c & 18.5 & $\mathrm{~b}$ & 96.8 & $\mathrm{bc}$ & 38.2 & $\mathrm{bc}$ & 45.6 & $\mathrm{c}$ \\
\hline
\end{tabular}

As for Prunus, clay amendment only affected plant dimensions (Tab. VII). The biggest width was in plants grown in control peat substrate, the biggest height in plants grown in the substrate F100. Limited branching could be due to lower available nutrients content (mainly phosphorus) in the clay amended substrates.

\section{CONCLUSIONS}

The results well document the effect of two clay products on properties of peat growing substrate. Both fine and coarse clay decreased available nutrients content, mainly content of available phosphorus. Both fine and coarse clay increased particle density and bulk density and decreased total pore space measured before planting as well as at the end of the experiment.

Fine clay strongly affected water holding characteristics. It increased difficultly available water and decreased easy available water. water buffering capacity. and air space. The effect of coarse clay was much weaker. It only decreased WBC and AS. Coarse clay limited substrate shrinkage.

The results show that substrate physical properties did not get worse during cultivation. At the end of the cultivation air space did not decrease. In case of the substrates sampled from containers with plants AS was even higher than sampled before planting. Shrinkage of all substrates was lower at the end than at the beginning of the cultivation.

In comparison with the relatively strong effect on the substrate chemical and physical properties the effect of clay addition on the growth and quality of model woody plants was not so explicit. Thuja plants grown in the substrates amended with clay were shorter and were lower in fresh weight and dry weight than plants in the control substrate. On the other hand in case of Prunus clay addition (fine and coarse) decreased plant width and increased plant height (only fine clay). 


\section{SUMMARY}

This work deals with the effect of two clay products differing in particle size distribution on properties of growing substrate and on growth of woody plants in 2-litre containers filled with the substrates amended with these clay products. The substrate prepared from blonde and black peat was amended with fine clay at rates 50 and $100 \mathrm{~kg} / \mathrm{m}^{3}$ or with coarse clay at rates 100 a $200 \mathrm{~kg} / \mathrm{m}^{3}$. The peat substrate without clay was used as a control. The substrates were tested in experiments with two woody ornamentals (Thuja occidentalis 'Smaragd' and Prunus cistena). Chemical and physical properties of the prepared substrates were measured according to European Standards before planting. Proportion of water categories differing in availability to the plants was calculated from retention curves measured on the sand box. Properties of substrates in containers with and without plants were evaluated in the same way at the end of the culture.

Clay addition changed physical and chemical properties of the tested substrates. The effect depended on grading and on the rate of the clay product. Clay addition decreased content of available nitrogen, potassium and mainly content of available phosphorus in substrates before planting. Both clay products increased particle density and bulk density and decreased total pore volume. Both clay products changed water holding characteristics, the effect of fine clay were much stronger. In the substrates sampled before planting fine clay increased difficultly available water and decreased easy available water, water buffering capacity, and air space. Coarse clay only decreased air space and water buffering capacity. Properties of the substrates from containers measured at the end of the culture were similar or even better than those before planting. Substrates from containers with plants were higher in air capacity. In comparison with the relatively strong effect on the substrate chemical and physical properties, the effect of clay addition on the growth and quality of model woody plants was not so explicit. Thuja plants grown in the substrates amended with clay were shorter and were lower in fresh weight and dry weight than plants in the control substrate. On the other hand in case of Prunus clay addition (fine and coarse) decreased plant width and increased plant height (only fine clay).

\section{Acknowledgment}

The work was realized in the framework of the specific research grant S with The Ministry of Education, Youth and Sports, Czech Republic.

Water retention curve measurement was performed within the framework of project No. 0002707301 supported by the Czech Ministry for the Environment.

\section{REFERENCES}

ALT, D., 1994: Eine neue rationelle AnalysenMethode. Deutscher Gartenbau, 48: 205-207.

BOHNE, H. and WREDE. A., 2005: Investigations of physical properties of growing substrates. European Journal of Horticultural Science, 70: 1-6.

CATIVELLO, C., 1995: Use of growing substrates with zeolites for seedling vegetables and pot plant production. Acta Horticulturae, 401: 251-257.

DE BOODT, M., VERDONCK, O. and CAPPAERT I., 1974: Method for measuring water release curve of organic substrates. Acta Horticulturae, 37: 20542062.

DIN 11540 Peats and peat products for horticulture and landscape gardening - Test methods, properties, specifications. 2009.

EN 13037 Soils improvers and growing media Determination of pH, CEN Brussels, 1999.

EN 13038 Soils improvers and growing media Determination of electrical conductivity, CEN Brussels, 1999.

EN 13041 Soils improvers and growing media Determination of physical properties - Dry bulk density, air volume, water volume, shrinkage value and total pore space, CEN Brussels, 1999.
EN 13651 Soils improvers and growing media Extraction of calcium chloride/DTPA (CAT) soluble nutrients, CEN Brussels, 2001.

EN 13652 Soils improvers and growing media - Extraction of water soluble nutrients and elements, CEN Brussels, 2001.

GRANTZAU, E., 1998a: Substrate und Rohstoffe. Ton und Tonminerale. Deutscher Gartenbau, 52 (29): 37-38.

GRANTZAU, E., 1998b: Tone für Substrate. Deutscher Gartenbau, 52 (49): 6-10.

HANSON, A.-N., HARRIS, J. R., WRIGHT, R. and NIEMIERA, A., 2004: Water content of a pinebark growing substrate in a drying mineral soil. HortScience, 39 (3): 591-594.

HEISKANEN, J., 1995: Physical properties of twocomponent growth media based on Sphagnum peat and their implication for plant-available water and aeration. Plant and Soil, 172: 45-54.

ISO/DIS 10390 Soil quality - Determination of $\mathrm{pH}$. International Organization for Standardization, 1992.

ISO/DIS 10693 Soil quality - Determination of carbonate content - volumetric method. International Organization for Standardization, 1993. 
ISO/DIS 13536 Soil quality - Determination of the potential exchange capacity and base saturation - Method according to Bascomb at pH 8.1. International Organization for Standardization, 1994.

KOLAR, M., DUBSKÝ, M., ŠRÁMEK, F. and PINTA, M., 2010: The Effect of Natural Zeolite in Peat Based Growing Media on Pelargonium zonale Plants. Europ.J.Hort.Sci., 75 (5): 226-230.

MARTÍNEZ, F. X., SEPÓ, N. and VALERO, J., 1997: Physical and physicochemical properties of peatcoir mixes and the effects of clay-material addition. Acta Horticulturae, 450: 39-46.

PASTOR, J. N., BURÉS, S., SAVÉ, R., MARFÀ, O. and PAGÈS, J. M., 1999: Transplant adaptation in landscape of ornamental shrubs in relation with substrate physical properties and container size. Acta Horticulturae, 481: 137-144.

PRASAD, M. and O'SHEA, J., 1999: Relative breakdown of peat and non-peat growing media. Acta Horticulturae, 481: 121-128.

ŠRÁMEK,F.,DUBSKÝ,M., WEBER,M.,DOSTÁLEK, J. and SKALOŠ, J., 2010: Peat-Reduced Substrates with Mineral Components for Growing of Woody Plants. Acta Horticulturae, 885: 361-366.

VERDONCK, O., PENNINCK, R. and DE BOODT, M., 1983: The Physical properties of different Horticultural Growing substrates. Acta Horticulturae, 150: 155-160.

VERHAGEN, J. B. G. M., 2004: Effectiveness of clay in peat based growing media. Acta Horticulturae, 644: 115-122.

\section{Address}

Ing. Tomáš Meisl, Katedra zahradnictví, Česká zemědělská univerzita v Praze, Kamýcká 129, 16521 Praha 6 Suchdol, Česká republika, Ing. Martin Dubský, Ph.D., RNDr. František Šrámek, CSc., Výzkumný ústav Silva Taroucy pro krajinu a okrasné zahradnictví, v. v. i., Květnové náměstí 391, 25243 Průhonice, Česká republika, Ing. Tomáš Nečas, Ph.D., Ústav ovocnictví, Mendelova univerzita v Brně, Valtická 337, 691 44 Lednice, Česká republika, e-mail:meisl@centrum.cz, dubsky@vukoz.cz, sramek@vukoz.cz,necast@zf.mendelu.cz 